\title{
Amodiaquine Hydrochloride
}

National Cancer Institute

\section{Source}

National Cancer Institute. Amodiaquine Hydrochloride. NCI Thesaurus. Code C65232.

The hydrochloride salt of amodiaquine, an orally active 4-aminoquinoline derivative with antimalarial and anti-inflammatory properties. Similar in structure and activity to chloroquine, amodiaquine is effective against some chloroquine-resistant strains, particularly Plasmodium falciparum, the most deadly malaria parasite. Although the mechanism of plasmodicidal action has not been fully elucidated, like other quinoline derivatives, amodiaquine likely is able to inhibit heme polymerase activity in the body. This results in accumulation of free heme, which is toxic to the parasites. 